\title{
Tetrahydrobiopterin-dependent preservation of nitric oxide-mediated endothelial function in diabetes by targeted transgenic GTP-cyclohydrolase I overexpression
}

\author{
Nicholas J. Alp, ${ }^{1}$ Shafi Mussa, ${ }^{1}$ Jeffrey Khoo, ${ }^{1}$ Shijie Cai, ${ }^{1}$ Tomasz Guzik, ${ }^{1}$ \\ Andrew Jefferson, ${ }^{2}$ Nicky Goh, ${ }^{1}$ Kirk A. Rockett, ${ }^{3}$ and Keith M. Channon ${ }^{1}$ \\ ${ }^{1}$ Department of Cardiovascular Medicine, University of Oxford, John Radcliffe Hospital, Oxford, United Kingdom \\ ${ }^{2}$ Molecular Cytogenetics and \\ ${ }^{3}$ Childhood Infection Group, Wellcome Trust Centre for Human Genetics, University of Oxford, Oxford, United Kingdom
}

\begin{abstract}
Increased production of reactive oxygen species and loss of endothelial NO bioactivity are key features of vascular disease states such as diabetes mellitus. Tetrahydrobiopterin (BH4) is a required cofactor for eNOS activity; pharmacologic studies suggest that $\mathrm{BH} 4$ may mediate some of the adverse effects of diabetes on eNOS function. We have now investigated the importance and mechanisms of BH4 availability in vivo using a novel transgenic mouse model with endothelial-targeted overexpression of the rate-limiting enzyme in $\mathrm{BH} 4$ synthesis, guanosine triphosphate-cyclohydrolase $\mathrm{I}$ (GTPCH). Transgenic (GCH-Tg) mice demonstrated selective augmentation of endothelial BH4 levels. In WT mice, induction of diabetes with streptozotocin (STZ) increased vascular oxidative stress, resulting in oxidative loss of $\mathrm{BH} 4$, forming $\mathrm{BH} 2$ and biopterin. Endothelial cell superoxide production in diabetes was increased, and NO-mediated endothelium-dependent vasodilatation was impaired. In diabetic GCH-Tg mice, superoxide production from the endothelium was markedly reduced compared with that of WT mice, endothelial BH4 levels were maintained despite some oxidative loss of $\mathrm{BH} 4$, and NO-mediated vasodilatation was preserved. These findings indicate that $\mathrm{BH} 4$ is an important mediator of eNOS regulation in diabetes and is a rational therapeutic target to restore NO-mediated endothelial function in diabetes and other vascular disease states.
\end{abstract}

J. Clin. Invest. 112:725-735 (2003). doi:10.1172/JCI200317786.

\section{Introduction}

Diabetes mellitus and other vascular disease states are characterized by loss of NO bioactivity, resulting in endothelial dysfunction (1). Since NO plays a central role in maintaining vascular homeostasis, loss of $\mathrm{NO}$ bioactivity contributes to vascular disease pathogenesis and is a marker of adverse outcome. NO is generated in the vascular wall by eNOS, which oxidizes L-arginine to L-citrulline using molecular oxygen. Although endothelial NO bioactivity is decreased in diabetes, levels of eNOS mRNA and protein are maintained or even

Received for publication January 7, 2003, and accepted in revised form June 10, 2003.

Address correspondence to: Keith M. Channon, Department of Cardiovascular Medicine, John Radcliffe Hospital, Oxford OX3 9DU, United Kingdom. Phone: 44-1865-851085; Fax: 44-1865-222077; E-mail: keith.channon@cardiov.ox.ac.uk. Conflict of interest: The authors have declared that no conflict of interest exists.

Nonstandard abbreviations used: tetrahydrobiopterin (BH4); guanosine triphosphate-cyclohydrolase I (GTPCH); transgenic (Tg); streptozotocin (STZ); 6-pyruvoyltetrahydropterin synthase (PTPS); dihydrobiopterin (BH2); murine embryonic fibroblast (MEF); reverse transcriptase (RT); isobutylmethylxanthine (IBMX); glycated hemoglobin content of blood samples $\left(\mathrm{HbA}_{1}\right)$; cardiac microvascular endothelial cell (CMEC); dihydroethidium (DHE); polyethylene glycol-conjugated superoxide dismutase (PEG-SOD); Krebs-Henseleit buffer (KHB); phenylephrine (PE); $\mathrm{N} \omega$-nitro-L-arginine methyl ester (L-NAME); reduced to oxidized glutathione ratio (GSH/GSSG). enhanced but are associated with reduced NO production and increased superoxide production due to enzymatic "uncoupling" of eNOS (2).

Tetrahydrobiopterin (BH4) is an essential cofactor for activity of all NOS enzymes (3). The exact role of BH4 in NOS catalysis remains incompletely defined, but it appears to facilitate electron transfer from the eNOS reductase domain and maintains the heme prosthetic group in its redox active form (4-6). Moreover, BH4 promotes formation of active NOS homodimers (7) and reduces superoxide production by "uncoupled" eNOS $(4,8)$. Intracellular BH4 levels are regulated by the activity of the de novo biosynthetic pathway. Guanosine triphosphate cyclohydrolase I (GTPCH, EC3.5.4.16) catalyzes GTP to dihydroneopterin triphosphate. BH4 is generated by further steps catalyzed by 6-pyruvoyltetrahydropterin synthase (PTPS) and sepiapterin reductase (9). GTPCH appears to be the rate-limiting enzyme in $\mathrm{BH} 4$ biosynthesis; overexpression of GTPCH is sufficient to augment BH4 levels in cultured endothelial cells (10).

Recent studies suggest that reduced BH4 availability in diabetes may be an important contributor to reduced NO production and increased endothelial superoxide production $(3,11)$. Some features of endothelial dysfunction are improved by high-concentration $\mathrm{BH} 4$ supplementation in vessel rings from animals with diabetes $(12,13)$ or atherosclerosis $(14)$ and 
in mammary artery rings from patients with diabetes (15). Acute BH4 administration appears to augment NO-mediated effects on forearm blood flow in patients with diabetes (16) or hypercholesterolemia (17). However, it remains difficult to determine the true mechanistic relationship between endothelial $\mathrm{BH} 4$ levels and eNOS regulation in vivo, because high extracellular $\mathrm{BH} 4$ concentrations may result in nonspecific antioxidant effects that indirectly increase NO bioactivity by ROS scavenging rather than by modulation of eNOS activity. Furthermore, the effects of supplementation with $\mathrm{BH} 4$ or biopterin analogues on $\mathrm{NO}$ bioactivity are unpredictable in vascular disease states in which oxidative stress is increased $(18,19)$. Indeed, it remains unclear whether adequate eNOS cofactor function in vivo is related to absolute $\mathrm{BH} 4$ levels in the endothelial cell, or whether the relative balance between reduced $\mathrm{BH} 4$ and oxidized dihydrobiopterin (BH2) may be more important (20). Oxidation of $\mathrm{BH} 4$ by reactive oxygen species such as peroxynitrite results in formation of $\mathrm{BH} 2$ that is inactive for eNOS cofactor function, raising the possibility that oxidative loss of $\mathrm{BH} 4$ may mediate some of the observed effects of increased reactive oxygen species production on endothelial function in vascular disease states $(14,21)$.

Accordingly, we sought to investigate the functional importance of endothelial $\mathrm{BH} 4$ levels in diabetic endothelial dysfunction using a novel approach to augment intracellular $\mathrm{BH} 4$ levels in endothelial cells in vivo without recourse to systemic high-concentration biopterin supplementation. We generated transgenic mice with endothelium-targeted GTPCH overexpression, and used these animals to investigate how changes in intracellular BH4 levels regulate NO-mediated endothelial function in experimental diabetes mellitus.

\section{Methods}

Animals. All studies involving laboratory animals were conducted in accordance with the United Kingdom Home Office Animals (Scientific Procedures) Act of 1986. Mice were housed in temperature-controlled cages

\section{Figure 1}

(a) Schematic of the murine Tie2 promoter-enhancer/human GTPCH transgene. The murine Tie2 promoter and its intronic enhancer (10 $\mathrm{kb}$ ) are depicted as gray bars, human GTPCH cDNA is depicted as a white bar, and SV40 poly A signal is depicted as a black bar. Oligonucleotide primers were used to screen genomic DNA for the presence of the transgene. Restriction endonuclease sites for Sall and Xbal are shown. GCH, GTPCH; PA, SV40 poly A; P1 and P2, oligonucleotide primers. (b) Genomic DNA analysis of potential founders. The top panel shows PCR reactions performed on DNA isolated from tail biopsies. The expected 150-bp product (filled arrowhead) was identified in founder mouse 16; linearized pTie2-GCH plasmid DNA was used as a positive control. The bottom panel shows Southern blot analysis performed to confirm the transgenic founders' genotype and estimate transgene copy number. Founder mouse 16 showed a single hybridization fragment of $8 \mathrm{~kb}$ (open arrowhead), suggesting a single chromosomal integration site. The pTie2-GCH plasmid digested with $\mathrm{Xbal}$ was used as a positive control. $\left(20-22^{\circ} \mathrm{C}\right)$ with a 12 -hour light-dark cycle and given free access to water and formulated diets. All experimental comparisons were made between transgenic and WT littermates that were 12-16 weeks of age.

Plasmid construction. To target GTPCH gene expression to the vascular endothelium, we constructed a GTPCH transgene incorporating the murine Tie2 promoter (22). A human GTPCH cDNA (0.7 kb, GenBank accession number S44049; kindly provided by $\mathrm{H}$. Ichinose) (23) was modified by PCR and subcloned to incorporate PstI and MluI sites at $5^{\prime}$ and $3^{\prime}$ ends, respectively. The plasmid pHHNS, comprising the murine Tie 2 promoter, LacZ cDNA, and SV40 polyA signal and a $10-\mathrm{kb}$ intronic enhancer from the murine Tie2 gene was generously provided by U. Deutsch (22). The LacZ coding sequence was removed from pHHNS by digestion with Sse 5357 I and MluI and replaced by directional cloning of the PstI-MluI human GTPCH cDNA. The resulting plasmid, pTie2-GCH, was confirmed by DNA sequencing using standard techniques.

Generation of transgenic mice. The Tie2-GCH transgene $(18 \mathrm{~kb})$ (Figure 1a) was excised from pTie2-GCH by SalI digestion and purified by sucrose density-gradient ultracentrifugation $(10-30 \% \mathrm{wt} / \mathrm{vol})$. The Tie2-GCH fragment was dissolved in sterile injection buffer ( 5 $\mathrm{mM}$ Tris/Cl [pH 7.5], $0.1 \mathrm{mM}$ EDTA) at $5 \mathrm{ng} / \mu \mathrm{l}$ for pronuclear microinjection in fertilized eggs from superovulated C57BL/ $6 \times$ CBA mice. Potential transgenic founders were screened by PCR of genomic DNA from tail tips, using primers specific for murine Tie2 promoter sequence (forward, 5'-GGGAAGTCGCAAAGTTGTGAGTT-3') and for human GTPCH (reverse, $5^{\prime}$ GAACCCATTGCTGCACCTGG-3'), producing a 150 -bp PCR product (Figure 1b).

Southern blotting. Potential founders identified by PCR screening were confirmed by Southern blotting. Genomic DNA was digested with XbaI (which has a single restriction site within the transgene) and probed with the 150-bp PCR product described above, labeled with [ $\left.{ }^{32} \mathrm{P}\right] \mathrm{dCTP}$ (Figure $1 \mathrm{~b}$ ).
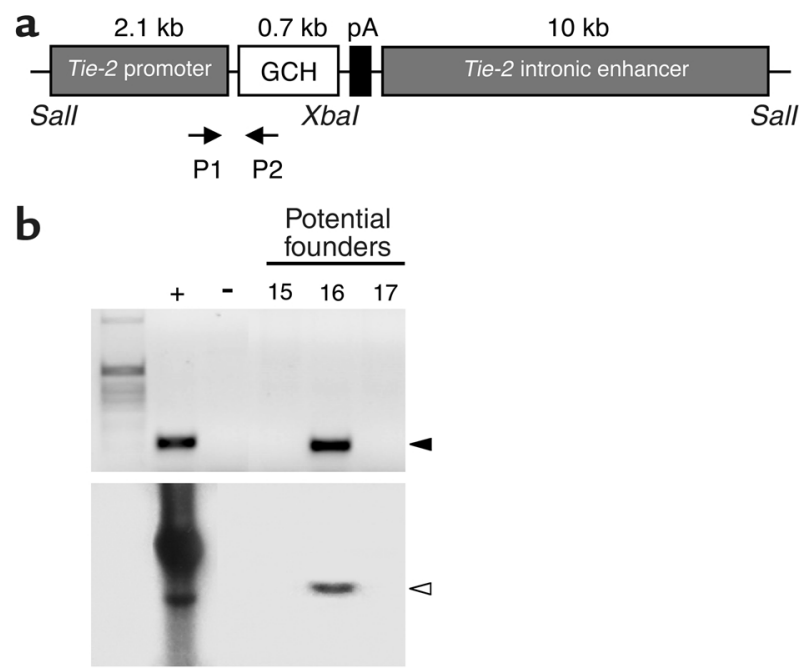
Fluorescent in situ bybridization. Fluorescent in situ hybridization was performed to identify the chromosomal site(s) of transgene integration into the mouse genome. Metaphase chromosome preparations were made from murine embryonic fibroblasts (MEFs). A Tie2-GCH probe (pTie2-GCH plasmid linearized with SalI) was biotinylated, hybridized using standard techniques, and then detected with Texas red-conjugated streptavidin (Molecular Probes Europe BV, Leiden, The Netherlands). Commercial FITC-labeled chromosome paints (Cambio Ltd., Cambridge, United Kingdom) were used to confirm the identity of chromosomes carrying integrations.

Quantitative real-time RT-PCR. Total RNA was extracted from frozen tissue (lung or liver) by homogenization in $1 \mathrm{ml}$ of Trizol solution (Sigma-Aldrich, St. Louis, Missouri, USA). For aorta, the vessel was excised, cleaned of fat, flushed with PBS, and opened longitudinally. The aorta was incubated for 5 minutes in $1 \mathrm{ml}$ of Trizol, and the residual tissue was removed. Total tissue RNA (100 ng), dissolved in RNase-free water, was used in RT-PCR (Qiagen Quantitect SYBR Green RTPCR kit, Qiagen, Crawley, United Kingdom) using the following primers for various GTPCH mRNA transcripts $\left(5^{\prime}-3^{\prime}\right)$ : human (transgenic): forward, CGCCTACTCGTCCATCCTGA; reverse, CCTTCACAATCACCATCTCA (product size, $181 \mathrm{bp}$ ); mouse (endogenous): forward, TGCTTACTCGTCCATTCTGC; reverse, CCTTCACAATCACCATCTCG (product size, 181 bp); universal (human and mouse): forward, TGCTCAAGACGCCCTGGAGG; reverse, AGGACTTGCTTGTTAGGAAG (product size, $217 \mathrm{bp}$ for human and $253 \mathrm{bp}$ for mouse). Quantitative fluorescent real-time RT-PCR analysis was performed to compare relative quantities of mRNA in mouse organs using the Rotor-Gene system (Corbett Research Ltd., Cambridge, United Kingdom). Samples were processed in triplicate, with a reverse transcriptase (RT) negative control reaction for each sample. For human GTPCH RT-PCR analysis, standards were prepared using 10-fold dilutions of total RNA prepared from 293 cells infected for 48 hours with a recombinant adenovirus encoding human GTPCH (10). For mouse GTPCH RT-PCR analysis, standards were prepared using 10-fold dilutions of C57Bl/6 mouse liver total RNA. Quantification was performed using proprietary software to generate standard curves, expressing relative quantities of PCR products in the experimental samples in arbitrary units relative to the standard curve. Mean values were calculated from triplicate samples to produce an $n$ of 1 . Results from at least three animals per group were pooled to produce means and SEMs.

Western blotting. Tissues were homogenized on ice for 30 minutes in a fourfold volume of extract buffer (50 $\mathrm{mM}$ Tris- $\mathrm{HCl}$ [pH 7.5], $150 \mathrm{mM} \mathrm{NaCl}$, sodium deoxycholate $1 \%$, SDS $[0.1 \% \mathrm{wt} / \mathrm{vol}]$, nonidet P40 [1\% $\mathrm{vol} / \mathrm{vol}$ ], $1 \mathrm{mM}$ dithiothreitol) containing protease inhibitors (Complete, Boehringer Mannheim, Grenzach-Eyhlen, Germany) and $1 \mathrm{mM}$ PMSF. For aorta, the whole vessel was opened longitudinally and rocked in $30 \mu \mathrm{l}$ of extract buffer for 30 minutes at $4{ }^{\circ} \mathrm{C}$. Protein lysates $(20-50 \mu \mathrm{g})$ were resolved using SDS-PAGE and transferred to PVDF membranes (Immobilon-P, Millipore, Bedford, Massachusetts, USA). Primary antibody incubations were performed using a 1:2,000 dilution of a rabbit anti-human GTPCH polyclonal antibody (a generous gift of G. Werner-Felmeyer, University of Innsbruck, Austria). Secondary antibody incubations were performed using a 1:2,500 dilution of goat antirabbit HRP conjugate (Promega, Madison, Wisconsin, USA). Protein bands were visualized by chemiluminescence (SuperSignal, Pierce, Rockford, Illinois, USA).

Measurement of biopterins and neopterin. Measurements of $\mathrm{BH} 4$ and $\mathrm{BH} 2$ were performed by HPLC analysis, after iodine oxidation in acidic or alkaline conditions, as previously described (10). Briefly, organs were harvested, snap-frozen in liquid nitrogen or dry ice, and stored at $-80^{\circ} \mathrm{C}$. Whole mouse blood (0.5-1.0 $\mathrm{ml}$ per mouse) was collected from the inferior caval vein. Blood samples were transferred into Eppendorf tubes on ice and centrifuged, and the plasma supernatant was stored at $-80^{\circ} \mathrm{C}$. Small samples $(30-50 \mathrm{mg})$ of tissue were cut from frozen organ specimens, homogenized immediately for 30 seconds in $500 \mu \mathrm{l}$ of ice-cold extract buffer (fresh $50 \mathrm{mM}$ Tris$\mathrm{HCl}$ [pH 7.4], 1mM DTT, and 1mM EDTA, containing $0.1 \mu \mathrm{M}$ neopterin [Sigma-Aldrich] as an internal recovery standard). Protein concentration was measured using the Bio-Rad protein assay. After deproteination, paired samples were subjected to oxidation with $1 \%$ iodine $/ 2 \% \mathrm{KI}$ under acidic and basic conditions. Biopterins were determined by HPLC in 5\% methanol/95\% water using a Spherisorb ODS-1 column (Waters Ltd., Elstree, United Kingdom) and fluorescence detection (350 nm excitation, $450 \mathrm{~nm}$ emission). For each assay, a standard curve of freshly-made tetrahydrobiopterin (Schirks Laboratories, Jonas, Switzerland; range, $10^{-7} \mathrm{M}$ to $10^{-9} \mathrm{M}$ ) was included using the same extract buffer. BH4 concentration, expressed as picomoles per milligram of protein, was calculated by subtracting $\mathrm{BH} 2$ plus biopterin from total biopterins. In some experiments, neopterin concentration in tissues was measured in the same way, but excluding $0.1 \mu \mathrm{M}$ neopterin from the extract buffer and using a neopterin standard curve.

Measurement of arginine-to-citrulline conversion. Measurement of arginine-to-citrulline conversion, which indicates the rate of NO synthesis, was performed in fresh whole aorta and homogenized lung as previously described (24). Freshly harvested aortas were opened longitudinally and incubated in $250 \mu \mathrm{l} \mathrm{Krebs-}$ HEPES buffer (consisting of [in mmol/l] $\mathrm{NaCl} 99, \mathrm{KCl}$ 4.7, $\mathrm{MgSO}_{4} 1.2, \mathrm{KH}_{2} \mathrm{PO}_{4} 1.0, \mathrm{CaCl}_{2} 1.9, \mathrm{NaHCO}_{3} 25$, glucose 11.1, Na-HEPES 20), with $1 \mu \mathrm{M}$ Ca ionophore A23187 (Sigma-Aldrich) and $5 \mu$ l of ${ }^{14} \mathrm{C}$-labelled L-arginine (Amersham Biosciences UK Ltd., Chalfont St. Giles, United Kingdom) for 90 minutes at $37^{\circ} \mathrm{C}$, and then the solution was harvested. Endothelium was 
lysed by three cycles of freeze-thawing in $250 \mu \mathrm{l}$ of water, which was added to the previous harvest. Sixty microliters of $10 \%$ trichloroacetic acid was added to deproteinate the samples, which were centrifuged, and the supernatant was collected. Mouse lung was perfused with cold Krebs-HEPES buffer and snap frozen. One hundred milligrams of tissue was homogenized in $1 \mathrm{ml}$ of Krebs-HEPES buffer on ice and centrifuged, and the supernatant was collected. Protein concentration was measured using the Bio-Rad protein assay. Five microliters of ${ }^{14} \mathrm{C}$-labelled L-arginine was added to $200 \mu \mathrm{l}$ of homogenate, incubated for 60 minutes at $37^{\circ} \mathrm{C}$, and then deproteinated with $60 \mu \mathrm{l}$ of $10 \%$ trichloroacetic acid. Samples were analyzed on a $250 \mathrm{~mm} \times 4 \mathrm{~mm}$ SCX300 cation-exchange column (Sigma-Aldrich) using a Beckman (High Wycombe, United Kingdom) HPLC system consisting of a 128 dual pump, 171 continuous-flow liquid scintillation detector, and System Gold Software version 6.4 (Beckman, High Wycombe, United Kingdom). Running conditions for elution at $1 \mathrm{ml}$ per minute were as follows: buffer A, $1 \mathrm{mM}$ citric acid [pH 2.2]; buffer B, 150 $\mathrm{mM}$ sodium citrate [pH 3.0]; gradient of $100 \% \mathrm{~A}$ for 12 minutes, $50 \% \mathrm{~A}$ and $50 \% \mathrm{~B}$ for 18 minutes, and $100 \%$ B for 2 minutes. The column was regenerated after each sample using $10 \mathrm{mM}$ citric acid for $10 \mathrm{~min}$ utes and $1 \mathrm{mM}$ citric acid for 17 minutes. Scintillant fluid was mixed after elution from the column, prior to passage through the detector, at $0.5 \mathrm{ml}$ per minute. Standards of ${ }^{14} \mathrm{C}$-labelled $\mathrm{L}$-arginine and citrulline were used to determine elution times. Citrulline peaks were integrated and expressed as a proportion of total ${ }^{14} \mathrm{C}$ counts for each sample.

Measurement of cyclic GMP levels. Cyclic GMP levels in aortas were measured as previously described $(25,26)$. Briefly, aortas were opened and preincubated for 15 minutes in oxygenated Krebs-HEPES solution with 0.1 $\mathrm{mmol} / \mathrm{l}$ isobutylmethylxanthine (IBMX) (SigmaAldrich) at $37^{\circ} \mathrm{C}$ and then stimulated with $1 \mu \mathrm{M}$ acetylcholine for 3 minutes. Vessels were immediately snap frozen in liquid nitrogen and homogenized in ice-cold $5 \%$ trichloroacetic acid containing $0.5 \mathrm{mM}$ IBMX. Homogenates were centrifuged at $2000 \mathrm{~g}$, and trichloroacetic acid in the supernatant fractions was extracted with water-saturated ether. Cyclic GMP levels were measured in these fractions using a cGMP enzyme immunoassay kit (Cayman Chemical Co., Nottingham, United Kingdom), and results were expressed as picomoles per milligram of TCA-precipitable protein solubilized with $1 \mathrm{M}$ sodium hydroxide.

Induction of diabetes by streptozotocin injection. A single high-dose streptozotocin (STZ) regimen was used to induce pancreatic islet cell destruction and persistent hyperglycemia, as previously described (27). STZ (10 $\mathrm{mg} / \mathrm{ml}$, Sigma-Aldrich) was freshly dissolved in sterile $0.025 \mathrm{M}$ sodium citrate buffer ( $\mathrm{pH} 4.5$ ) and used within 10 minutes. Mice received a single $160 \mathrm{mg} / \mathrm{kg}$ intraperitoneal injection of STZ or citrate buffer (control). Blood glucose was monitored weekly using a one- touch blood glucose meter (Lifescan). Hyperglycemia was defined as a random blood glucose level of more than $20 \mathrm{mmol} / \mathrm{l}$ for more than 3 weeks after injection. Organs were harvested 4 weeks after STZ injection. Total glycated hemoglobin content of blood samples $\left(\mathrm{HbA}_{1}\right)$ was measured using a commercially available kit (Sigma-Aldrich). Other biochemical analyses were performed on heparinized blood plasma using a Cobas Mira Plus automated analyzer (F. Hoffman-La Roche Ltd., Basel, Switzerland).

Cell culture. MEFs were prepared from 15-day-old embryos by trypsin-EDTA digestion of embryonic tissue. MEFs were cultured in DMEM supplemented with $2 \mathrm{mM}$ L-glutamine, 100,000 IU/1 penicillin, and 100 $\mathrm{mg} / 1$ streptomycin (Sigma-Aldrich) containing 10\% FCS (Sigma-Aldrich) and used at passages 3-5.

Freshly isolated mouse cardiac microvascular endothelial cells (CMECs) and myocytes were obtained using differential enzymatic digestion and centrifugation, as previously described (28). Briefly, for each preparation, three mice were euthanized and perfused with physiological saline, and the hearts were excised. The ventricles were minced and digested with collagenase three times, and then supernatants from each digestion were centrifuged at $25 \mathrm{~g}$ for 3 minutes. The myocyte-enriched cell pellet was washed and frozen at $-80^{\circ} \mathrm{C}$. For CMEC isolation, the residual ventricular tissue was digested with trypsin/EDTA solution, centrifuged at $25 \mathrm{~g}$ for $3 \mathrm{~min}$ utes, and the supernatant containing CMEC cells was centrifuged again at $120 \mathrm{~g}$ for 7 minutes to obtain a cell pellet, which was washed and frozen.

Tissue glutathione concentrations. Tissue concentrations of glutathione (total, reduced, and oxidized) were measured in aortic homogenates, after deproteinization with metaphosphoric acid in an enzymatic recycling method using glutathione reductase, as previously described (29). Values were normalized to protein concentration. Lucigenin-enhanced chemiluminescence detection of superoxide. Superoxide anion in mouse aorta was measured using $10 \mu \mathrm{M}$ lucigenin-enhanced chemiluminescence, as previously described (15). Thoracic aortas were harvested, flushed with Krebs-HEPES buffer, and divided into two $5-\mathrm{mm}$ rings. The rings were gassed with $95 \%$ oxygen $/ 5 \%$ carbon dioxide in warmed Krebs-HEPES buffer for 30 minutes before measurement of chemiluminescence in an FB12 luminometer (Berthold Detection Systems, Pforzheim, Germany). Baseline readings were obtained for 4 minutes before adding vessel rings, and then rings were allowed to equilibrate and dark adapt for 5 minutes before recording mean chemiluminescence for 10 minutes. Results were expressed as counts per second per milligram of dry weight.

Oxidative fluorescent microtopography. Superoxide production in tissue sections of aorta was detected using the fluorescent probe dihydroethidium (DHE), as previously described (15). Fresh segments of mouse aorta were frozen in optimal cutting temperature compound. Sections $(30 \mu \mathrm{m})$ were incubated in a light-protected chamber at $37^{\circ} \mathrm{C}$ for 10 minutes with $2 \mu \mathrm{M}$ 
DHE (Molecular Probes). Some sections were also incubated with $500 \mathrm{U} / \mathrm{ml}$ polyethylene glycol-conjugated superoxide dismutase (PEG-SOD) (Sigma-Aldrich) to demonstrate specificity of DHE fluorescence for superoxide. Images were obtained using a Bio-Rad MRC-1024 laser scanning confocal microscope equipped with a krypton/argon laser, using identical acquisition settings. DHE fluorescence was quantified by automated image analysis using Image-Pro Plus software (Media Cybernetics UK, Finchampstead, United Kingdom). For low-power $(\times 10)$ images, total DHE fluorescence throughout the whole aortic section (intensity by area) was measured. For quantification of endothelial cell fluorescence from high-power $(\times 60)$ images, DHE fluorescence (intensity by area) was measured only on the luminal side of the internal elastic lamina. For each vessel, mean fluorescence was calculated from four separate high-power fields taken in each quadrant of the vessel to produce an $n$ of 1 .

Isometric tension vasomotor studies. Aortic vasomotor function was analyzed using isometric tension studies. Two rings, each $2 \mathrm{~mm}$ in length, were cut from the midpoint of each thoracic aorta and mounted in organ bath chambers (Multi-Myograph 610M, Danish Myo Technology, Aarhus, Denmark) containing $5 \mathrm{ml}$ of KrebsHenseleit buffer (KHB [in mmol/l]: $\mathrm{NaCl} 120, \mathrm{KCl} 4.7$, $\mathrm{MgSO}_{4} 1.2, \mathrm{KH}_{2} \mathrm{PO}_{4} 1.2, \mathrm{CaCl}_{2} 2.5, \mathrm{NaHCO}_{3} 25$, glucose $5.5)$ at $37^{\circ} \mathrm{C}$, gassed with $95 \% \mathrm{O}_{2} / 5 \% \mathrm{CO}_{2}$. All experiments were performed in the presence of $10 \mu \mathrm{M}$ indomethacin to inhibit vascular prostaglandin synthesis. After mounting, rings were allowed to equilibrate for 30 minutes and then stretched to a passive tension of 15 $\mathrm{mN}$ over 30 minutes. Vessel rings were constricted with $60 \mathrm{mM} \mathrm{KCl}$, typically achieving a contraction of 4-6 mN of active tension after 5 minutes; this value was used to correct subsequent responses for each ring. Dose-response contraction curves were established using cumulative half-log concentrations of phenylephrine (PE, $10^{-9}$ to $\left.10^{-5} \mathrm{M}\right)$. Vessels were washed three times with fresh $\mathrm{KHB}$, equilibrated for 30 minutes, and then precontracted to approximately $90 \%$ of maximal tension with PE (typically $3 \times 10^{-6} \mathrm{M}$ ). Acetylcholine was used to stimulate endothelium-dependent relaxations, mediated by endothelial NO release, in increasing cumulative concentrations $\left(10^{-9}\right.$ to $\left.10^{-5} \mathrm{M}\right)$. Responses were expressed as a percentage of the precontracted tension. After three washes, vessels were precontracted again with $\mathrm{PE}$, and $10^{-4} \mathrm{M} \mathrm{N} \omega$-nitro-L-arginine methyl ester (L-NAME) (Sigma-Aldrich) was added to inhibit endogenous NOS activity. Finally, the NO donor sodium nitroprusside $\left(10^{-10}\right.$ to $\left.10^{-6} \mathrm{M}\right)$ was added to test endothelium-independent smooth muscle relaxation to exogenous nitric oxide.

Statistical analysis. For isometric tension studies, the mean responses of two rings from each animal were combined to produce an $n$ of 1 . Dose-response curves from groups were compared using a general linear model ANOVA test for repeated measures (SPSS version 10.0, SPSS Inc., Chicago, Illinois, USA). Bonfer- roni post hoc correction was applied when three or more data sets were compared. For other comparisons, one-way ANOVA was used with Bonferroni post hoc correction as appropriate. $P$ values of less than 0.05 were considered significant. Data are expressed as means and SEMs.

\section{Results}

Generation of endothelium-specific GTPCH transgenic mouse lines. Potential GTPCH-transgenic (GCH-Tg) founder mice were screened by PCR and Southern blotting of genomic DNA from tail biopsies (Figure 1b). Four independent $\mathrm{GCH}-\mathrm{Tg}$ founders were identified from more than 150 pups born after pronuclear injection and embryo transfer. GCH-Tg line 16 was selected for the experiments presented here on the basis of preliminary phenotyping of tissue biopterin levels. Southern blotting showed a single $8 \mathrm{-kbp} \mathrm{XbaI} \mathrm{digestion} \mathrm{product,}$ suggesting a single transgene integration (Figure $1 \mathrm{~b}$ ). Fluorescent in situ hybridization revealed that the transgene was indeed integrated at a single site close to the centromere of chromosome 11 (data not shown). A breeding colony was established by crossing onto a $\mathrm{C} 57 \mathrm{Bl} / 6 \mathrm{~J}$ background, and all experiments were performed with heterozygous GCH-Tg mice, with the use of WT littermates as controls. There were no apparent morphological abnormalities in GCH-Tg mice. Male and female mice appeared equally fertile, and there were no differences in behavior, growth rate, or lifespan as compared with WT littermates.

Expression of GTPCH $m R N A$ and protein production. To determine whether GTPCH mRNA was expressed in GCH-Tg mice, we performed RT-PCR on total RNA extracted from lung, liver, and aorta - three organs with different proportions of endothelial cells. To distinguish native from transgenic message, we designed PCR primers specific for each transcript; to determine total GTPCH mRNA, we designed primers to hybridize with homologous sequences in both mouse and human GTPCH. Transgenic human GTPCH mRNA was detected in all organs from GCH-Tg animals but not in WT mice, whereas native murine GTPCH mRNA was detected in organs from both GCH-Tg and WT animals (Figure 2a). To determine the relative levels of native and transgenic GTPCH mRNA expression, we performed quantitative RT-PCR. In GCH-Tg mice, there was a 10-fold higher relative expression of transgenic human GTPCH in lung as compared with liver and aorta, most likely reflecting the increased proportion of endothelial cells in this tissue. Transgenic message was undetectable in WT mice. Native murine GTPCH expression in liver was 10 -fold higher than in lung and 100-fold higher than in aorta, consistent with known high levels of GTPCH activity in hepatocytes. However, there were no differences in native GTPCH expression in any organ between GCH-Tg and WT mice, suggesting that expression from the transgene had no effect on transcriptional regulation of the native gene. Total GTPCH expression (native plus 
a
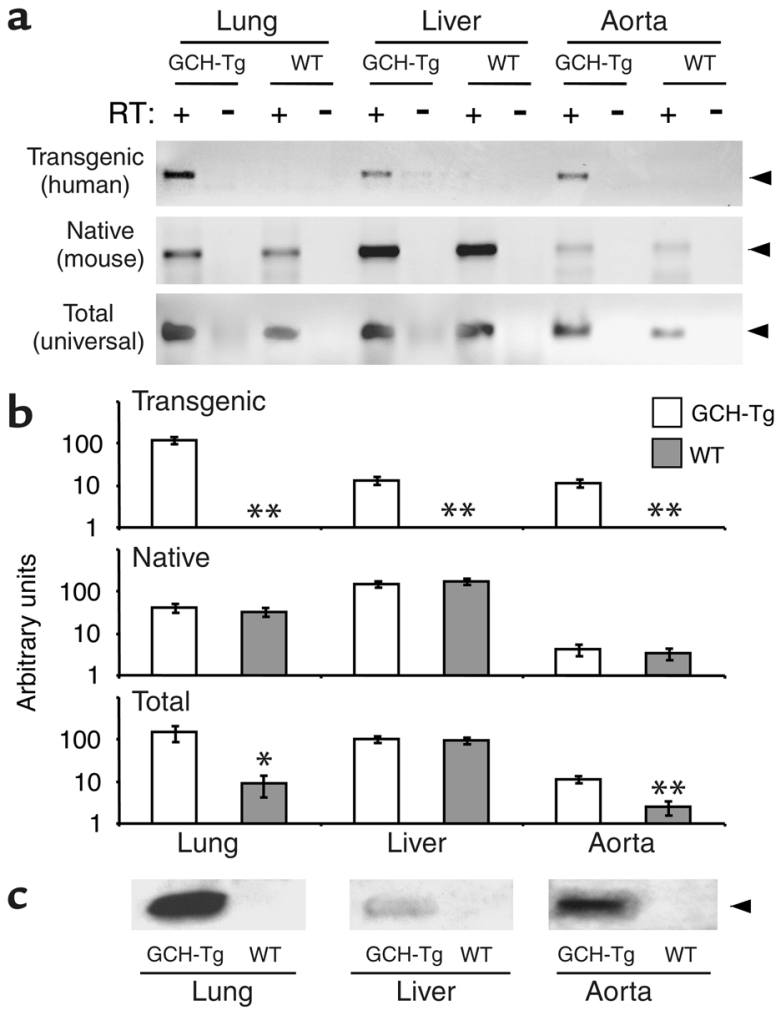

transgenic) in GCH-Tg mice was approximately 10 -fold higher in lung and 5-fold higher in aorta as compared with WT. In liver, there was no significant difference in total GTPCH expression between GCH-Tg and WT mice, reflecting the high contribution of native GTPCH expression in hepatocytes as compared with transgenic GTPCH expression in proportionately fewer endothelial cells (Figure 2b). Western blotting, using a rabbit anti-human GTPCH primary antibody, demonstrated human GTPCH protein in lung, liver, and aorta of GCH-Tg but not WT mice. Relative protein levels were highest in lung, consistent with the pattern of mRNA expression and again reflecting the high proportion of endothelial cells in this tissue (Figure 2c).

Biopterin levels in transgenic tissues and cells. We next determined whether increased GTPCH expression in $\mathrm{GCH}-\mathrm{Tg}$ mice would lead to increased $\mathrm{BH} 4$ production, by measuring biopterins in homogenates of snapfrozen tissue and in plasma. In all measurements, $\mathrm{BH} 4$ comprised $60-80 \%$ of the total biopterin content $(\mathrm{BH} 4$, $\mathrm{BH} 2$, and biopterin). $\mathrm{BH} 4$ levels were approximately threefold higher in GCH-Tg lung, heart, and aorta than in WT, with the highest absolute levels detected in GCH-Tg lung, consistent with higher levels of GTPCH mRNA and protein in this tissue (Figure 3 ). In contrast, there were no differences between GCH-Tg and WT $\mathrm{BH} 4$ levels in either liver or plasma, suggesting that endothelium-targeted GTPCH overexpression did not result in systemic increases in $\mathrm{BH} 4$.

To further demonstrate the endothelial specificity of transgenic GTPCH overexpression, we measured BH4 levels in the microvascular endothelial cell and myocyte

\section{Figure 2}

(a) Evaluation of transgenic and native GTPCH mRNA expression by RT-PCR. The top panel shows human-specific primers to detect transgenic GTPCH mRNA. A PCR product of $181 \mathrm{bp}$ (arrowhead) was detected in lung and liver, and aorta from $\mathrm{GCH}-\mathrm{Tg}$ but not WT littermates, and only after the RT step $(R T+)$. The middle panel shows mouse-specific primers used to detect native GTPCH mRNA. A PCR product of $181 \mathrm{bp}$ (arrowhead) was detected in lung, liver, and aorta from both GCH-Tg and WT mice. (b) Quantification of GTPCH expression by real-time fluorescent RT-PCR. Shown are means and SEMs of three samples, each quantified in triplicate. Note that arbitrary units are independent among the three graphs. In the top panel, transgenic GTPCH mRNA expression was 10-fold higher in lung than in liver and aorta among GCH-Tg animals but was not detected in WT littermates ( ${ }^{*} P<0.01$ for comparisons). In the middle panel, native GTPCH mRNA expression in liver was approximately 10 -fold higher than in lung and 100 -fold higher than in aorta, but similar between GCH-Tg and WT mice for each organ. In the bottom panel, total GTPCH mRNA expression in the lung was approximately 20 -fold higher in $\mathrm{GCH}-\mathrm{Tg}$ than in WT mice ( $\left.{ }^{*} P<0.05\right)$; in the liver there was no difference in $\mathrm{GCH}-\mathrm{Tg}$ as compared with WT mice; in the aorta, there was a 5-fold increase in total GTPCH mRNA expression in GCH-Tg as compared with WT mice $\left({ }^{*} P<0.01\right)$. (c) Immunoblotting with a rabbit anti-human GTPCH polyclonal antibody to detect transgenic GTPCH protein identified a specific $35-\mathrm{kDa}$ band (arrowhead) in lysates from lung, liver, and aorta from GCH-Tg but not WT animals.

fractions isolated directly from mouse hearts. $\mathrm{BH} 4 \mathrm{lev}-$ els were significantly higher in the endothelial cell fraction from GCH-Tg than in WT mice $(8.7 \pm 3.5$ vs. $3.2 \pm 1.3$ $\mathrm{pmol} / \mathrm{mg}$ of protein; $P<0.05, n=3$ ). In contrast, there was no difference in BH4 levels in the myocyte-enriched fraction between GCH-Tg and WT mice ( $0.7 \pm 0.3$ vs. $0.4 \pm 0.3 \mathrm{pmol} / \mathrm{mg}$ of protein), and the myocyte $\mathrm{BH} 4$ levels were markedly lower than endothelial cell levels $(P<0.01)$. Thus, for these comparisons between different cell types within one organ, GTPCH activity appeared highly specific for endothelial cells.

Neopterin levels were similar in GCH-Tg and WT lung $(2.5 \pm 1.7 \mathrm{vs} .1 .5 \pm 1.0 \mathrm{pmol} / \mathrm{mg}$ of protein, respectively; $P=$ not significant, $n=3)$ and aorta $(0.9 \pm 0.1$ vs. $1.2 \pm 0.1$ $\mathrm{pmol} / \mathrm{mg}$ of protein; $P=$ not significant, $n=3$ ), suggesting that subsequent enzymes in the $\mathrm{BH} 4$ biosynthetic pathway were not rate limiting in transgenic mice.

eNOS activity in transgenic mice. To determine the effect of increased endothelial $\mathrm{BH} 4$ levels on eNOS activity, we measured arginine-to-citrulline conversion by eNOS, using HPLC with on-line scintillation detection to enhance sensitivity and specificity of citrulline detection. In these experiments, arginine-to-citrulline conversion could be inhibited over $90 \%$ by the addition of $100 \mu \mathrm{M}$ L-NAME, confirming the NOS specificity of the reaction (data not shown). Citrulline production was increased twofold in stimulated GCH-Tg aorta as compared with WT (Figure 4a). A similar pattern was seen in freshly homogenized lung not supplemented with additional NOS cofactors (Figure $4 \mathrm{~b}$ ). These results indicated that increased endothelial BH4 levels were able to modestly enhance eNOS activity even in healthy mice. 


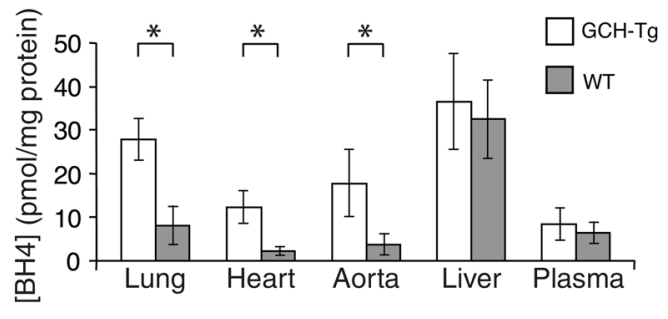

Figure 3

$\mathrm{BH} 4$ levels in $\mathrm{GCH}-\mathrm{Tg}$ and WT mouse tissues. Organs and plasma were harvested, and $\mathrm{BH} 4$ levels were determined by iodine oxidation in acid and base followed by HPLC. BH4 levels were increased threefold in $\mathrm{GCH}-\mathrm{Tg}$ lung, heart, and aorta as compared with WT $\left({ }^{*} P<0.05, n=3-4\right)$ but not in liver or plasma.

In contrast to the increased eNOS activity in GCH-Tg aortas, cGMP levels were not increased in GCH-Tg as compared with WT aortas $(59.3 \pm 7.8$ vs. $56.4 \pm 8.2$ $\mathrm{pmol} / \mathrm{mg}$ of protein; $P=$ not significant, $n=5)$. This suggested that other mechanisms may have attenuated the NO-to-cGMP signal transduction pathway.

Induction of diabetes using streptozotocin. We next investigated the vascular effects of experimental diabetes, using STZ treatment as a well-validated model of hyperglycemia in mice (27). In preliminary experiments, a single intraperitoneal injection of $160 \mathrm{mg} / \mathrm{kg}$ STZ resulted in sustained blood glucose concentrations of more than $20 \mathrm{mM}$ in over $80 \%$ of mice. STZ treatment significantly increased plasma cholesterol, glucose, and blood $\mathrm{HbA}_{1}$ levels as compared with citrate buffer control mice (Table 1). However, there were no differences between the responses of GCH-Tg mice and their WT littermates in any of these parameters.

Oxidative stress and superoxide production in diabetic aortas. To determine the effects of diabetes on vascular oxidative stress, we measured reduced to oxidized glutathione (GSH/GSSG) ratios in aortas. The GSH/ GSSG ratio was significantly lower in diabetic than in control aortas of WT mice, indicating increased oxidative stress. In contrast, the GSH/GSSG ratio was maintained in diabetic aortas of GCH-Tg mice, indicating a reduction in overall vascular oxidative stress in transgenic mice (Figure 5a). To determine the source of increased oxidative stress in diabetes, we next measured superoxide production from control and diabetic aortas. Lucigenin-enhanced chemiluminescence assays showed a greater than twofold increase in superoxide release from diabetic WT aortas as compared with control (Figure 5b). Superoxide production was also increased in diabetic GCH-Tg aortas but significantly less than the increase in WT animals $(P<0.05$ as compared with control and with diabetic WT). To investigate the contribution of endothelial cells to net superoxide production, we visualized superoxide production in fresh-frozen sections of mouse aorta using oxidative fluorescent microtopography. Diabetes increased DHE fluorescence throughout all layers of the vessel wall that was inhibited by preincubation with PEG-SOD (data not shown). Quantification of DHE fluorescence by automated image analysis revealed a two- to threefold increase in superoxide production in both diabetic WT and GCH-Tg mice as compared with their respective controls (Figure 5c). However, superoxide production imaged specifically in endothelial cells was strikingly increased, by more than 17 -fold in diabetic WT aorta, whereas endothelial superoxide production in diabetic GCH-Tg aorta was increased only 3.5-fold as compared with control (Figure 5d). These observations suggest that diabetes increases total vascular superoxide production, with a disproportionate increase in endothelial superoxide production in WT diabetic aorta that is prevented in GCH-Tg aorta.

Effect of streptozotocin-induced diabetes on GTPCH expression and aortic biopterin levels. We next investigated the effect of vascular oxidative stress, induced by diabetes, on GTPCH expression and on the levels and fate of biopterins in the vascular wall. Quantitative RT-PCR demonstrated that diabetes had no effect on total GTPCH mRNA expression in mouse aorta. However, total GTPCH mRNA levels were fivefold higher in GCH-Tg than in WT mice aortas (Figure 6a). In keeping with this observation, total biopterin levels, comprising $\mathrm{BH} 4, \mathrm{BH} 2$, and biopterin, were similar in diabetic and control aortas, although they were again approximately threefold higher in GCH-Tg than in WT (Figure 6b). In contrast, diabetes had a striking effect on the oxidative state of aortic biopterins, reflected in the proportion of $\mathrm{BH} 4$ in relation to biopterin and $\mathrm{BH} 2$. In diabetic WT mice aorta, virtually all detectable biopterins were present as $\mathrm{BH} 2$ and biopterin, so that $\mathrm{BH} 4$ was almost undetectable. Oxidative loss of $\mathrm{BH} 4$ to $\mathrm{BH} 2$ and biopterin was also observed in diabetic $\mathrm{GCH}-\mathrm{Tg}$ mice, with BH 4 comprising only $10 \%$ of the total biopterin content as compared with $80 \%$ in control GCH-Tg mice, but absolute levels of $\mathrm{BH} 4$ were nevertheless maintained at readily detectable levels. Thus, diabetes did not alter levels of total vascular biopterins, suggesting that de novo synthesis of biopterins was unaffected. Rather, loss of $\mathrm{BH} 4$ in diabetes was the result of
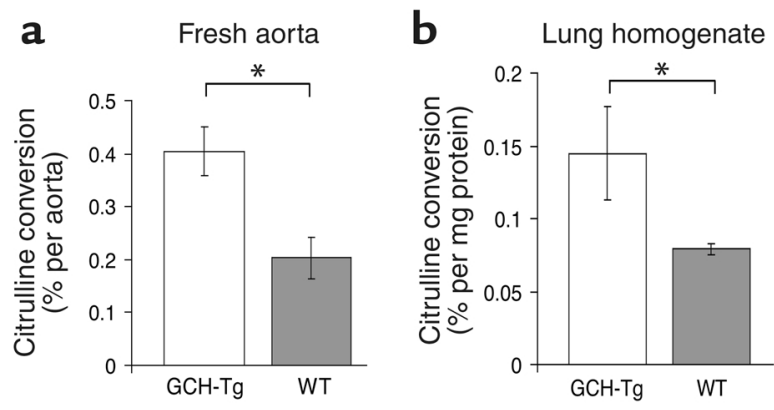

\section{Figure 4}

Arginine-to-citrulline conversion as a measure of eNOS activity. (a) Citrulline production was increased twofold in $\mathrm{GCH}-\mathrm{Tg}$ as compared with WT aortas stimulated with Ca ionophore for 90 minutes $\left({ }^{*} P=0.012\right.$, $n=5-6)$. (b) Basal citrulline production was increased in $\mathrm{GCH}-\mathrm{Tg}$ as compared with WT lung protein homogenate $\left({ }^{*} P<0.05, n=3\right)$. 
Table 1

Biochemical data from GCH-Tg mice and WT littermates, 4 weeks after induction of diabetes using STZ (diabetic) or after buffer injection (control)

\begin{tabular}{lrcrr} 
& \multicolumn{2}{c}{ GCH-Tg } & \multicolumn{2}{c}{ WT } \\
& Control & \multicolumn{1}{c}{ Diabetic } & \multicolumn{1}{c}{ Control } & \multicolumn{1}{c}{ Diabetic } \\
& $(n=6-8)$ & $(n=4-6)$ & $(n=6-8)$ & $(n=4-6)$ \\
Creatinine $(\mu \mathrm{mol} / \mathrm{l})$ & $29.7 \pm 9.2$ & $43.7 \pm 14.9$ & $27.8 \pm 7.5$ & $32.4 \pm 4.8$ \\
Total cholesterol $(\mathrm{mmol} / \mathrm{I})$ & $2.4 \pm 0.1$ & $3.6 \pm 0.4^{\mathrm{A}}$ & $2.3 \pm 0.5$ & $3.3 \pm 0.6^{\mathrm{B}}$ \\
$\mathrm{HDL}$ cholesterol $(\mathrm{mmol} / \mathrm{l})$ & $1.4 \pm 0.1$ & $2.4 \pm 0.2^{\mathrm{A}}$ & $1.4 \pm 0.2$ & $2.1 \pm 0.5^{\mathrm{B}}$ \\
Triglycerides $(\mathrm{mmol} / \mathrm{l})$ & $1.2 \pm 0.4$ & $2.2 \pm 1.1$ & $1.6 \pm 0.4$ & $2.3 \pm 1.4$ \\
Glucose $(\mathrm{mmol} / \mathrm{l})_{\mathrm{HbA}_{1}(\%)}^{5.9 \pm 1.8}$ & $27.8 \pm 6.0^{\mathrm{A}}$ & $6.7 \pm 3.1$ & $30.1 \pm 4.5^{\mathrm{C}}$ \\
& $4.8 \pm 0.5$ & $7.4 \pm 1.5^{\mathrm{A}}$ & $4.7 \pm 0.2$ & $6.1 \pm 0.5^{\mathrm{C}}$ \\
\hline
\end{tabular}

${ }^{A} P<0.01$ for diabetic compared with control GCH-Tg. ${ }^{B} P<0.05$ for diabetic compared with control WT. $C P<0.01$ for diabetic compared with control WT.

oxidation to $\mathrm{BH} 2$ and biopterin. However, increased $\mathrm{BH} 4$ synthesis and reduced endothelial superoxide production in diabetic GCH-Tg mice prevented complete $\mathrm{BH} 4$ loss even in the presence of increased vascular oxidative stress.

Endothelial function in diabetic aortas. We next determined the functional relationships between changes in $\mathrm{BH} 4$ metabolism in diabetes and eNOS-dependent vasomotor function. Isometric tension studies demonstrated no difference in vascular contractions to PE among the four groups of mice. However, endothelium-dependent relaxations to the receptormediated eNOS agonist acetylcholine were significantly impaired in diabetic WT mice as compared with controls (Figure 7, a and b). In contrast, endothelium-dependent relaxations remained normal in diabetic GCH-Tg mice, suggesting preserved eNOS function. Endothelium-independent relaxations to the NO donor sodium nitroprusside were identical in all groups, demonstrating no difference in vascular smooth muscle responses to NO (Figure 7, $\mathrm{c}$ and d). These observations indicate that maintenance of endothelial BH4 levels preserves NO-mediated endothelial function in diabetic GCH-Tg mice, despite increased vascular oxidative stress.

\section{Discussion}

In this paper, we describe the generation of a new transgenic mouse model in which human GTPCH overexpression is targeted to endothelial cells under the control of the mouse Tie 2 promoter. We used this model to investigate the role of $\mathrm{BH} 4$ in diabetic endothelial dysfunction, and we report the following major findings. First, endothelium-specific overexpression of GTPCH is sufficient to increase BH4 levels in vascular tissues in vivo and to increase NOS activity. Second, increasing endothelial BH4 synthesis by targeted GTPCH overexpression does not increase systemic BH4 levels in plasma or nonvascular tissues, thus avoiding the potentially confounding nonspecific effects of high-level systemic BH4 supplementation. Third, experimental diabetes does not have a major effect on total vascular biopterins but increases vascular oxidative stress, leading to oxi- dation of $\mathrm{BH} 4$, forming $\mathrm{BH} 2$ and biopterin. In WT mice, this oxidation results in almost undetectable levels of $\mathrm{BH} 4$, but in $\mathrm{GCH}-\mathrm{Tg}$ mice, modest BH4 levels are maintained despite increased vascular oxidative stress, and this is associated with greatly reduced superoxide production from the endothelium (Figure 5d). Fourth, depletion of BH4 and increased endothelial superoxide production in diabetic WT mice are associated with deficient NOmediated endothelial function, which is prevented by maintenance of endothelial $\mathrm{BH} 4$ levels in diabetic GCH-Tg mice.

These findings provide important insights into the role of $\mathrm{BH} 4$ in vascular homeostasis and into the mechanisms underlying endothelial dysfunction in diabetes and other vascular disease states. Deficient NO-mediated endothelial function is a characteristic feature of diabetes. Several studies suggest that diabetes in both humans and experimental models is associated with increased vascular oxidative stress, which reduces $\mathrm{NO}$ bioactivity by direct scavenging of $\mathrm{NO}$ by superoxide, resulting in the formation of the reactive peroxynitrite radical. Important sources of vascular superoxide such as vascular $\mathrm{NAD}(\mathrm{P}) \mathrm{H}$ oxidases are upregulated in diabetes $(13,15)$. However, recent findings also suggest that eNOS regulation is abnormal in diabetes, resulting in a direct contribution by eNOS to vascular superoxide production, and that this eNOS dysfunction is related to reduced BH4 availability (13, 15). In diabetic rats, $\mathrm{BH} 4$ levels are low both in aorta (30) and in isolated endothelial cells (31), in association with reduced $\mathrm{NO}$ bioactivity and increased superoxide production. Pharmacological administration of $\mathrm{BH} 4$ in vitro or by repeated dosing in vivo partially corrects these abnormalities. However, in these studies neither the mechanisms underlying the loss of $\mathrm{BH} 4$ in diabetes nor the relationship between endothelial versus systemic BH4 effects was clear. Recent important studies in hypercholesterolemic rabbit aorta, in which $\mathrm{BH} 4$ levels were also low, found that $\mathrm{BH} 4$ supplementation using high-dose sepiapterin resulted in a paradoxical worsening of NO-mediated endothelial function, mediated by possible adverse effects of sepiapterin on eNOS function and on the relative balance of oxidized versus reduced biopterins in the vascular wall (18). In atherosclerotic mouse aorta, Laursen et al. observed eNOSdependent superoxide production that was reproduced by exposure of aortic rings to peroxynitrite, suggesting that oxidative radicals promote eNOS uncoupling (14). Indeed, both superoxide and peroxynitrite can oxidize BH4 under physiological conditions $(14,21,32)$.

By direct quantification of biopterin, $\mathrm{BH} 2$, and $\mathrm{BH} 4$, we now find that diabetes is indeed associated with a striking reduction of aortic $\mathrm{BH} 4$ levels, but with no change in total biopterin levels or vascular GTPCH 

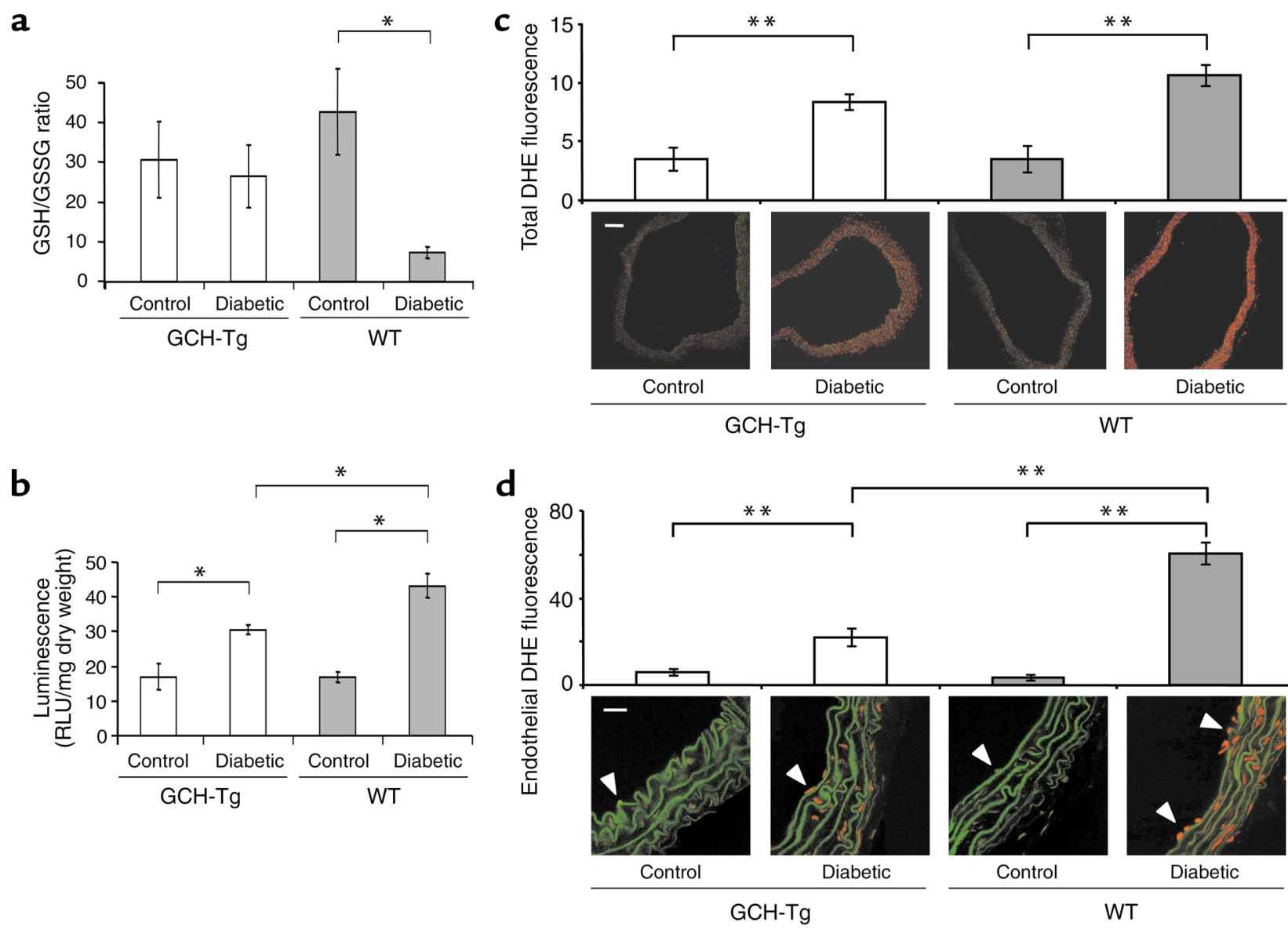

\section{Figure 5}

Oxidation of glutathione stores and superoxide generation in aorta from diabetic GCH-Tg and WT mice. (a) The GSH/GSSG ratio was reduced in diabetic WT mice as compared with control WT mice ( $\left.{ }^{*} P=0.02, n=3\right)$, but diabetes did not alter the GSH/GSSG ratio in GCH-Tg mice. (b) Lucigenin-enhanced chemiluminescence. Superoxide production in control WT aortas was similar to that in GCH-Tg aortas. Superoxide production was increased more than twofold in diabetic WT aortas as compared with control $\left({ }^{*} P<0.05\right)$, but this increase was significantly smaller in diabetic GCH-Tg aortas $\left({ }^{*} P<0.05\right.$ as compared with control and with diabetic WT, $\left.n=4-6\right)$. RLU, relative light units. (c) DHE staining for whole-vessel superoxide production. Representative sections are shown $(\times 10)$, with total red DHE fluorescence expressed in arbitrary units. Aortic DHE fluorescence was increased two- to threefold in both diabetic WT and GCH-Tg mice as compared with their respective controls ( ${ }^{*} P<0.01, n=3$ ). Scale bar: $100 \mu \mathrm{m}$. (d) DHE staining for endothelial cell superoxide production. Representative sections are shown $(\times 60)$, with specific endothelial cell red DHE fluorescence (arrowheads) expressed in arbitrary units. Endothelial DHE fluorescence was increased by more than 17-fold in diabetic WT aorta, whereas endothelial superoxide production in diabetic GCH-Tg aorta was increased only 3.5 -fold as compared with control $\left({ }^{*} P<0.01, n=3\right)$. Elastic laminas exhibit green autofluorescence. Scale bar: $20 \mu \mathrm{m}$.

expression, indicating that the mechanism of $\mathrm{BH} 4$ loss in vivo is oxidative conversion of $\mathrm{BH} 4$ to $\mathrm{BH} 2$ and biopterin rather than a change in biosynthesis of biopterins per se. Furthermore, transgenic augmentation of $\mathrm{BH} 4$ biosynthesis in the endothelium resulted in a three- to fourfold increase in total biopterin levels, with a proportionate elevation in $\mathrm{BH} 4$ in control animals. In diabetes, increased biopterin synthesis in the endothelium by targeted GTPCH overexpression does not completely prevent $\mathrm{BH} 4$ oxidation. Rather, increased BH4 biosynthesis is sufficient to maintain detectable $\mathrm{BH} 4$ levels despite some oxidative $\mathrm{BH} 4$ loss and is sufficient to rescue the functional deficit in NOmediated endothelial function and greatly reduce the striking increase in endothelial superoxide production. The markedly reduced endothelial superoxide produc- tion we observed in diabetic GCH-Tg endothelium suggests that eNOS uncoupling is prevented by maintaining adequate $\mathrm{BH} 4$ levels, despite the increase in total vascular oxidative stress induced by diabetes $(13,15)$.

Some studies have suggested that $\mathrm{BH} 4$ availability may not be the key determinant of BH4-mediated eNOS regulation but that the relative concentration of $\mathrm{BH} 2$ may also play a role, because $\mathrm{BH} 2$ is inactive as an eNOS cofactor and may compete with BH4 for eNOS binding in vitro (20). However, in experiments using high-level supplementation of $\mathrm{BH} 4$ or its precursor sepiapterin in vascular disease, the functional importance of the $\mathrm{BH} 4$ to $\mathrm{BH} 2 /$ biopterin ratio may be confounded by direct effects on eNOS function and by indirect effects on cellular redox balance (18). Our approach to genetically modify intrinsic endothelial 
a
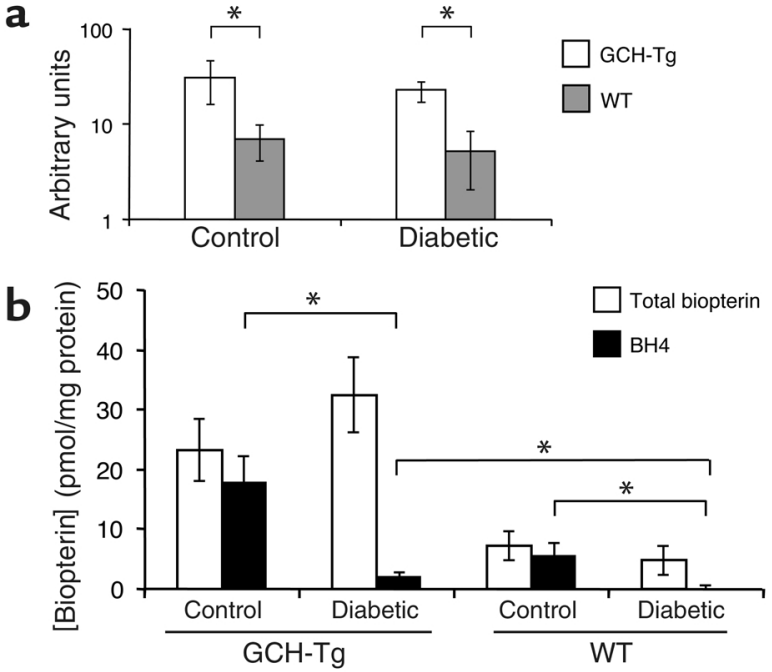

Figure 6

Effect of diabetes on GTPCH expression and aortic biopterins. (a) Total GTPCH mRNA levels in aorta from diabetic or control GCH-Tg mice and WT littermates were determined by quantitative RT-PCR and plotted on a log scale. Total GTPCH mRNA levels were increased fivefold in GCH-Tg as compared with WT mice ( ${ }^{*} P<0.05, n=3$ ), but diabetes did not affect GTPCH expression in either group. (b) Total biopterin and $\mathrm{BH} 4$ levels in aorta from diabetic or $\mathrm{GCH}-\mathrm{Tg}$ transgenic mice and WT littermates. There was a threefold increase in total biopterin levels in GCH-Tg aortas as compared with WT. Diabetes had no effect on total biopterin levels as compared with control in either group. However, in WT diabetic aortas, $\mathrm{BH} 4$ was almost undetectable, and $\mathrm{BH} 4$ levels in diabetic $\mathrm{GCH}-\mathrm{Tg}$ aortas were significantly reduced as compared with control $\left({ }^{*} P<0.05, n=4-6\right)$.

BH4 biosynthesis in vivo provides data to address this issue, by elevating BH4 levels in the endothelium and then subjecting the endothelium to increased oxidative stress in a model of diabetes. The low but detectable vascular BH4 levels that we observed in the aortas from $\mathrm{GCH}-\mathrm{Tg}$ diabetic mice were sufficient to maintain normal eNOS function, as demonstrated by normal NOmediated vasorelaxations in organ chamber studies and by a specific reduction in endothelial superoxide production. Indeed, the ratio of $\mathrm{BH} 4$ to $\mathrm{BH} 2 /$ biopterin was greatly reduced by oxidative stress in diabetic aortas from either WT or GCH-Tg animals, whereas impaired NO-mediated vascular function and greatly increased endothelial superoxide production were observed only in diabetic WT animals. These observations suggest that the absolute availability of $\mathrm{BH} 4$, rather than the relative concentration of $\mathrm{BH} 4$ in relation to $\mathrm{BH} 2 /$ biopterin, is the principal determinant of eNOS activity and maintenance of enzymatic coupling.

Our experiments indicate that targeted transgenic GTPCH overexpression is indeed sufficient to increase endothelial $\mathrm{BH} 4$ to supraphysiologic levels in vivo. Although GTPCH is considered to be the rate-limiting enzyme in $\mathrm{BH} 4$ biosynthesis, previous evidence in cultured endothelial cells does not exclude other potential regulatory or rate-limiting steps in the pathway that could be unmasked by transgenic overexpression of
GTPCH in vivo. By analogy, human monocyte/macrophage cells strongly upregulate GTPCH expression and activity in response to inflammatory stimuli (33). However, the next enzyme in the pathway, PTPS, becomes rate limiting in these cells, and its substrate, dihydroneopterin triphosphate, accumulates and is oxidized to neopterin. In GCH-Tg mice, there was no evidence of neopterin accumulation as compared with WT littermates, suggesting that subsequent enzymes in the synthetic pathway did not become limiting in endothelium, despite GTPCH overexpression. Nevertheless, we observed only a relatively modest (3- to 4fold) increase in tissue BH4 levels in GCH-Tg mice, in the setting of a 5- to 10-fold increase in total GTPCH mRNA levels. This suggests that the activity of transgenic GTPCH may be regulated posttranscriptionally or posttranslationally, for example, by GTPCH feedback regulatory protein (34).

We used an endothelium-targeted transgenic strategy to restrict GTPCH overexpression and hence $\mathrm{BH} 4$ augmentation to the vascular wall, thus avoiding the potentially confounding effects of high-level, systemic $\mathrm{BH} 4$ augmentation. Indeed, we found that tissue $\mathrm{BH} 4$ levels were increased in GCH-Tg mice only in organs
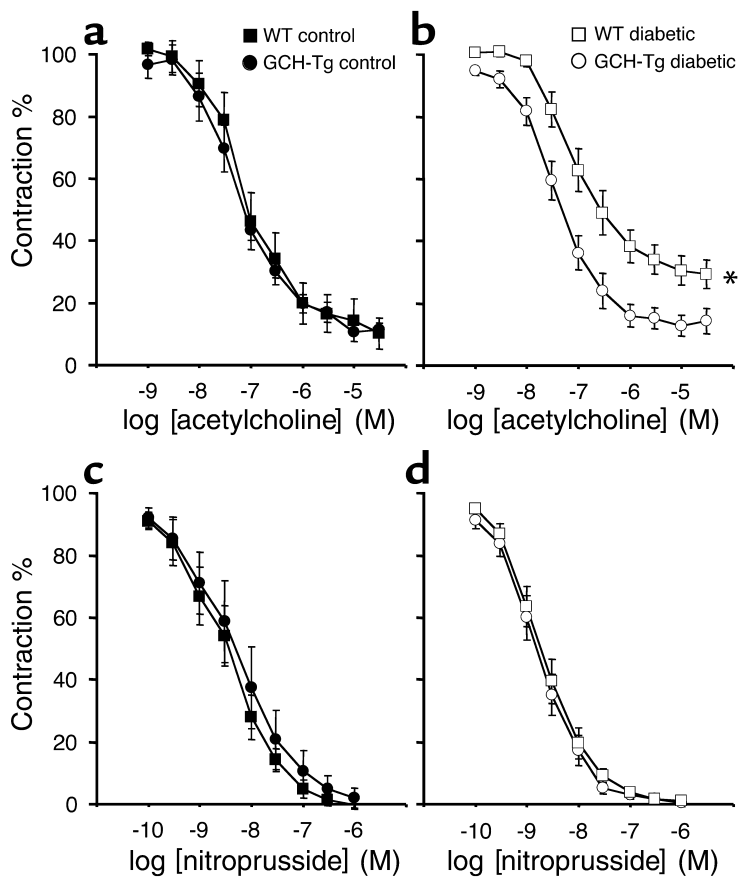

\section{Figure 7}

Isometric tension studies in aortic rings from diabetic and control $\mathrm{GCH}-\mathrm{Tg}$ and WT mice ( $n=5-8$ animals per group). (a) Vessel relaxations to the endothelium-dependent agonist acetylcholine were normal in control GCH-Tg (filled circles) and WT mice (filled squares). (b) Diabetic WT mice (open squares) exhibited impaired endotheliumdependent relaxations as compared with $\mathrm{GCH}-\mathrm{Tg}$ mice (open circles) $\left({ }^{*} P=0.002\right)$ and with control WT mice (filled squares, $P=0.048$ ). There was no difference in endothelium-dependent relaxations between diabetic and control GCH-Tg mice (open and filled circles, respectively; $P=0.468$ ). ( $($ and $\mathbf{d}$ ) Vessel relaxations to the NO donor sodium nitroprusside were identical in all groups of mice. 
with a high proportion of endothelial cells, and they were not increased in plasma or in tissues such as liver where high levels of intrinsic hepatocyte BH4 biosynthesis are the principal determinant of total organ BH4 levels. Furthermore, even in endothelium-rich tissues, or in isolated endothelial cells, the levels of $\mathrm{BH} 4$ were increased only a two- to four-fold, illustrating that the GCH-Tg mouse is a model of modest continuous endothelial, as opposed to systemic, augmentation of $\mathrm{BH} 4$. Our finding that increased endothelial $\mathrm{BH} 4$ levels are associated with modest increases in NO production raises the possibility that eNOS activity is closely coupled to BH4 concentration, even in healthy vasculature. Thus, the GCH-Tg mouse offers a unique approach to investigating the role of $\mathrm{BH} 4$ in modulating eNOS activity.

We conclude that availability of $\mathrm{BH} 4$ within the vascular endothelium is critical in maintaining eNOS function and reducing endothelial superoxide production in vascular disease states such as diabetes. Loss of BH4 in diabetes is the consequence of increased vascular oxidative stress rather than decreased biosynthesis of biopterins. Maintaining sufficient endothelial BH4 levels, even in the presence of substantial oxidative stress, is a valid strategy to maintain or restore the integrity of NO-mediated endothelial function in diabetes.

\section{Acknowledgments}

This work was supported by the British Heart Foundation. N.J. Alp is a Wellcome Trust Cardiovascular Research Initiative Training Fellow. We are grateful to Ian Smith and Jonathan Kay for assistance with HPLC.

1. Harrison, D.G. 1998. Cellular and molecular mechanisms of endothelial dysfunction. J. Clin. Invest. 100:2153-2157.

2. Cosentino, F., Hishikawa, K., Katusic, Z.S., and Luscher, T.F. 1997. High glucose increases nitric oxide synthase expression and superoxide anion generation in human aortic endothelial cells. Circulation. 96:25-28.

3. Cosentino, F., and Luscher, T.F. 1999. Tetrahydrobiopterin and endothelial nitric oxide synthase activity. Cardiovasc. Res. 43:274-278.

4. Vasquez-Vivar, J., et al. 1998. Superoxide generation by endothelial nitric oxide synthase: the influence of cofactors. Proc. Natl. Acad. Sci. U. S. A. 95:9220-9225.

5. Stuehr, D.J. 1999. Mammalian nitric oxide synthases. Biochim. Biophys. Acta. 1411:217-230.

6. Stuehr, D., Pou, S., and Rosen, G.M. 2001. Oxygen reduction by nitricoxide synthases. J. Biol. Chem. 276:14533-14536.

7. Tzeng, E., Billiar, T.R., Robbins, P.D., Loftus, M., and Stuehr, D.J. 1995. Expression of human inducible nitric oxide synthase in a tetrahydrobiopterin (H4B)-deficient cell line - H4B promotes assembly of enzyme subunits into an active enzyme. Proc. Natl. Acad. Sci. U. S. A. 92:11771-11775.

8. Wever, R.M.F., van Dam, T., van Rijn, H.J., de Groot, F., and Rabelink, T.J. 1997. Tetrahydrobiopterin regulates superoxide and nitric oxide generation by recombinant endothelial nitric oxide synthase. Biochem. Biophys. Res. Commun. 237:340-344.

9. Thony, B., Auerbach, G., and Blau, N. 2000. Tetrahydrobiopterin biosynthesis, regeneration and functions. Biochem. J. 347:1-16.

10. Cai, S., et al. 2002. GTP cyclohydrolase I gene transfer augments intracellular tetrahydrobiopterin in human endothelial cells: effects on nitric oxide synthase activity, protein levels and dimerization. Cardiovasc. Res. 55:838-849.
11. Katusic, Z.S. 2001. Vascular endothelial dysfunction: does tetrahydrobiopterin play a role? Am. J. Physiol. Heart Circ. Physiol. 281:H981-H986.

12. Shinozaki, K., et al. 1999. Abnormal biopterin metabolism is a major cause of impaired endothelium-dependent relaxation through nitric oxide $/ \mathrm{O}_{2}^{-}$imbalance in insulin-resistant rat aorta. Diabetes. 48:2437-2445.

13. Hink, U., et al. 2001. Mechanisms underlying endothelial dysfunction in diabetes mellitus. Circ. Res. 88:E14-E22.

14. Laursen, J.B., et al. 2001. Endothelial regulation of vasomotion in apoEdeficient mice: implications for interactions between peroxynitrite and tetrahydrobiopterin. Circulation. 103:1282-1288.

15. Guzik, T.J., et al. 2002. Mechanisms of increased vascular superoxide production in human diabetes mellitus: role of $\mathrm{NAD}(\mathrm{P}) \mathrm{H}$ oxidase and endothelial nitric oxide synthase. Circulation. 105:1656-1662.

16. Heitzer, T., Krohn, K., Albers, S., and Meinertz, T. 2000. Tetrahydrobiopterin improves endothelium-dependent vasodilation by increasing nitric oxide activity in patients with Type II diabetes mellitus. Diabetologia. 43:1435-1438.

17. Stroes, E., et al. 1997. Tetrahydrobiopterin restores endothelial function in hypercholesterolemia. J. Clin. Invest. 99:41-46.

18. Vasquez-Vivar, J., Duquaine, D., Whitsett, J., Kalyanaraman, B., and Rajagopalan, S. 2002. Altered tetrahydrobiopterin metabolism in atherosclerosis: implications for use of oxidized tetrahydrobiopterin analogues and thiol antioxidants. Arterioscler. Thromb. Vasc. Biol. 22:1655-1661.

19. Tarpey, M.M. 2002. Sepiapterin treatment in atherosclerosis. Arterioscler. Thromb. Vasc. Biol. 22:1519-1521.

20. Vasquez-Vivar, J., Martasek, P., Whitsett, J., Joseph, J., and Kalyanaraman, B. 2002. The ratio between tetrahydrobiopterin and oxidized tetrahydrobiopterin analogues controls superoxide release from endothelial nitric oxide synthase: an EPR spin trapping study. Biochem. J. 362:733-739.

21. Milstien, S., and Katusic, Z. 1999. Oxidation of tetrahydrobiopterin by peroxynitrite: implications for vascular endothelial function. Biochem. Biophys. Res. Commun. 263:681-684.

22. Schlaeger, T.M., et al. 1997. Uniform vascular-endothelial-cell-specific gene expression in both embryonic and adult transgenic mice. Proc. Natl. Acad. Sci. U. S. A. 94:3058-3063.

23. Togari, A., Ichinose, H., Matsumoto, S., Fujita, K., and Nagatsu, T. 1992. Multiple mRNA forms of human GTP cyclohydrolase I. Biochem. Biophys. Res. Commun. 187:359-365.

24. Rockett, K.A., et al. 1998. 1,25-Dihydroxyvitamin D3 induces nitric oxide synthase and suppresses growth of Mycobacterium tuberculosis in a human macrophage-like cell line. Infect. Immun. 66:5314-5321.

25. Leopold, J.A., Zhang, Y.Y., Scribner, A.W., Stanton, R.C., and Loscalzo, J. 2003. Glucose-6-phosphate dehydrogenase overexpression decreases endothelial cell oxidant stress and increases bioavailable nitric oxide. Arterioscler. Thromb. Vasc. Biol. 23:411-417.

26. Ohashi, Y., et al. 1998. Hypotension and reduced nitric oxide-elicited vasorelaxation in transgenic mice overexpressing endothelial nitric oxide synthase. J. Clin. Invest. 102:2061-2071.

27. Soriano, F.G., Pacher, P., Mabley, J., Liaudet, L., and Szabo, C. 2001. Rapid reversal of the diabetic endothelial dysfunction by pharmacological inhibition of poly(ADP-ribose) polymerase. Circ. Res. 89:684-691.

28. Li, J.M., Mullen, A.M., and Shah, A.M. 2001. Phenotypic properties and characteristics of superoxide production by mouse coronary microvascular endothelial cells. J. Mol. Cell. Cardiol. 33:1119-1131.

29. Weiss, N., et al. 2002. Cellular redox state and endothelial dysfunction in mildly hyperhomocysteinemic cystathionine beta-synthase-deficient mice. Arterioscler. Thromb. Vasc. Biol. 22:34-41.

30. Shinozaki, K., et al. 2000. Oral administration of tetrahydrobiopterin prevents endothelial dysfunction and vascular oxidative stress in the aortas of insulin-resistant rats. Circ. Res. 87:566-573.

31. Meininger, C.J., et al. 2000. Impaired nitric oxide production in coronary endothelial cells of the spontaneously diabetic BB rat is due to tetrahydrobiopterin deficiency. Biochem. J. 349:353-356.

32. Vasquez-Vivar,J., Whitsett, J., Martasek, P., Hogg, N., and Kalyanaraman, B. 2001. Reaction of tetrahydrobiopterin with superoxide: EPR-kinetic analysis and characterization of the pteridine radical. Free Radic. Biol. Med. 31:975-985.

33. Werner, E.R., et al. 1991. Biochemistry and function of pteridine synthesis in human and murine macrophages. Pathobiology. 59:276-279.

34. Milstien, S., Jaffe, H., Kowlessur, D., and Bonner, T.I. 1996. Purification and cloning of the GTP cyclohydrolase I feedback regulatory protein, GFRP. J. Biol. Chem. 271:19743-19751. 